\section{MERCANTILIZACIÓN Y EXPANSIÓN DE LA INQUILINIZACIÓN INFORMAL EN VILLAS DE BUENOS AIRES, ARGENTINA ${ }^{1}$}

María Carla Rodríguez², María Florencia

Rodríguez $^{3}$ y María Cecilia Zapata ${ }^{4}$

\section{Resumen}

La presencia extendida de urbanizaciones informales ha caracterizado históricamente el proceso de crecimiento y consolidación de las ciudades latinoamericanas. Inicialmente, estas modalidades de autoproducción de la ciudad respondían prioritariamente a la lógica de satisfacción de necesidades básicas del hábitat, sin embargo, su progresiva consolidación implicó el despliegue de lógicas mercantilizadoras informales de acceso al suelo y la vivienda, entre ellas, el alquiler. Este artículo tiene por objetivo caracterizar la dinámica que asumió durante la última década el proceso de inquilinización informal de villas en la ciudad de Buenos Aires, tomando en cuenta el perfil de

\section{COMMODIFICATION AND EXPANSION OF INFORMAL TENANCY IN THE INFORMAL SETTLEMENTS OF BUENOS AIRES, ARGENTINA ${ }^{1}$}

\author{
María Carla Rodríguez ${ }^{2}$, María Florencia \\ Rodríguez ${ }^{3}$ and María Cecilia Zapata ${ }^{4}$
}

\section{Abstract}

The widespread presence of informal settlements has historically characterized the growth and consolidation process of Latin American cities. Initially, these self-production methods placed priority on the satisfaction of basic needs; however, the progressive consolidation experienced by these spaces triggered the emergence of informal commodification models to secure access to land and housing, such as tenancy. This paper aims to characterize the dynamic that governed the informal tenancy process in different settlements of Buenos Aires over the last decade by analyzing the profiles of relevant actors (tenants, offering parties and mediators) and the forms adopted by tenancy 
los principales actores que intervienen (inquilinos, oferentes y mediadores) y las modalidades que adopta la práctica cotidiana del alquiler (circuitos, condiciones y arreglos económicos). En los casos estudiados por esta investigación (villas 31 y 31 bis, 20, 3, 21-24 y Rodrigo Bueno), todos producidos sobre tierras de propiedad pública, se constata una creciente heterogeneidad de actores y arreglos que van consolidado, por la vía de las prácticas, un proceso de apropiación privatizadora del suelo y profundización de la desigualdad intraterritorial, que se instala como un desafío para las políticas urbanas con enfoques de derechos.

\section{PALABRAS CLAVE: MERCANTILIZACIÓN, VILLAS, ALQUILER INFORMAL.}

Recibido: 21/10/2016

Aceptado: 12/12/2017

1 Esta investigación recupera datos longitudinales del proyecto de investigación UBACYT "Territorio, políticas habitacionales y transformaciones urbanas en principales áreas metropolitanas de Argentina (AMBA y Córdoba)", del cual las autoras son integrantes. Además, recupera información de una encuesta producida desde el Consejo Económico y Social de la Ciudad de Buenos Aires durante el año 2015.

2 Argentina. Instituto de Investigaciones Gino Germani (IIGG), Facultad de Ciencias Sociales, Universidad de Buenos Aires. Investigadora CONICET. ORCID: https://orcid.org/0000-0002-0124-5312. Correo electrónico: trebol1968@gmail.com.

3 Argentina. Instituto de Investigaciones Gino Germani (IIGG), Facultad de Ciencias Sociales, Universidad de Buenos Aires, CONICET. ORCID: https://orcid.org/0000-0002-6410-5931. Correo electrónico: mafloro@ gmail.com.

4 Argentina. Instituto de Investigaciones Gino Germani (IIGG), Facultad de Ciencias Sociales, Universidad de Buenos Aires. Investigadora CONICET. ORCID: https://orcid.org/0000-0003-0580-6938. Correo electrónico: ceciliazapata@gmail.com. on a daily basis (circuits, conditions and economic agreements.) The cases analyzed in this paper (Settlement 31 and 31 bis, 20, 3, 21-24 and Rodrigo Bueno, all built on public lands) reveal a growing heterogeneity among actors and agreements that consolidate, through practices, a private land appropriation process and the exacerbation of intra-territorial inequalities, thus posing a challenge to rights-based urban policies.

\section{KEYWORDS: COMMODIFICATION, INFORMAL SETTLEMENTS, INFORMAL TENANCY.}

Received: 21-10-2016

Accepted: 12-12-2017

1 This research collects longitudinal data from the UBACyT research project entitled "Territory, Housing Policies and Urban Transformations in Main Metropolitan Areas of Argentina (AMBA and Córdoba)", developed by the authors of this paper. This research also collects data from a survey conducted by the Social and Economic Council of Buenos Aires in 2015.

2 Argentina. Gino Germani Research Institute (IIGG), Faculty of Social Sciences, University of Buenos Aires. Researcher, CONICET. ORCID: https://orcid.org/0000-0002-0124-5312. Email: trebol1968@gmail.com.

3 Argentina. Gino Germani Research Institute (IIGG), Faculty of Social Sciences, University of Buenos Aires. Researcher, CONICET. ORCID: https://orcid.org/0000-0002-6410-5931.Email: mafloro@gmail.com.

4 Argentina. Gino Germani Research Institute (IIGG), Faculty of Social Sciences, University of Buenos Aires. Researcher, CONICET. ORCID: https://orcid.org/0000-0003-0580-6938. Email: ceciliazapata@gmail. com. 


\section{Introducción}

Desde mediados de los setenta las ciudades -en especial las latinoamericanas- se convirtieron en espacios privilegiados para el despliegue del negocio y la especulación financiera, mediante un proceso de mercantilización extendida de los bienes y servicios necesarios para la reproducción de la vida (Harvey, 2004 y 2010; Pradilla Cobos, 2010; Amín, 2003). En este escenario, las villas ${ }^{5}$, con su persistencia y expansión en la Ciudad de Buenos Aires (CABA), constituyeron una forma de integración precaria de los sectores populares en los márgenes de la centralidad urbana, que se reconfiguró bajo las modalidades del "neoliberalismo realmente existente" (Theodore, Peck y Brenner, 2009).

El presente artículo tiene por objetivo caracterizar la dinámica que asumió la inquilinización informal de villas en la Ciudad de Buenos Aires, durante los últimos diez años. En efecto, en los últimos años ha crecido significativamente el mercado informal "secundario" dentro de las distintas formas de ocupaciones directas, debido a que en muchas ciudades no es posible la ocupación de más suelo,

5 Entendemos por "villas" a urbanizaciones autoproducidas a partir de ocupaciones de tierra vacante, mediante prácticas individuales y diferidas en el tiempo, con particularidades en su conformación (trama urbana irregular, en áreas con buena localización sobre tierras fiscales; poseen alta densidad poblacional; cuyos pobladores poseen bajo nivel educativo y alto nivel de precarización laboral (Cravino, 2006, p. 36-37). porque ya no existe. Varias investigaciones señalan que los asentamientos informales se densifican, por un lado, y por otro aparece el mercado informal dentro de los mismos (en villas, favelas, callampas, entre otros) tanto de compra-venta como de alquiler (Clichevsky, 2008; Cravino, 2006; Abramo, 2003).

La hipótesis que guía este trabajo es que la valorización sostenida del precio del suelo en la CABA durante esa etapa, dinamizada por las políticas urbanas neoliberales, encareció el acceso a la vivienda en propiedad y alquiler "formal" e indujo las mismas tendencias sobre los mercados informales. De este modo, el alquiler informal en villas se consolidó como única alternativa para las franjas de más bajos ingresos de la población y como una oportunidad de captación de renta para quienes pudieran producir dicha oferta informal. Estas prácticas, consolidan y naturalizan la privatización del uso del suelo público.

La expansión de las prácticas de alquiler informal tienden a consolidar, en los usos cotidianos y costumbres, la figura de los propietarios informales, o tal como los designa el censo, "propietarios de 
la vivienda solamente". Los inquilinos aceptan dichos arreglos por encontrarse excluidos de otras opciones de resolución de su necesidad habitacional -hoteles pensión, alquiler formal o programas públicos-. Por su parte, entre los propietarios, se configuran distintos perfiles que van desde la resolución de la reproducción de la economía doméstica familiar hasta el desarrollo de un negocio privado a partir de la inversión de capital informal, pero que tienen en común estar basados en la obtención de una renta. En los casos abordados por esta investigación, el proceso se ha desarrollado sobre suelo de propiedad pública, por lo cual la expansión de este entramado de actores y arreglos introduce mayor heterogeneidad y complejidad, profundizando la progresiva apropiación y privatización del suelo en condiciones altamente desreguladas, que han sido favorecidas por la omisión del Estado y sus políticas públicas.

El artículo se estructura en cinco partes. En primer lugar, se abordan las dinámicas y transformaciones de las ciudades habilitadas por el neoliberalismo; posteriormente, se analiza el crecimiento socio-demográfico de las villas de los últimos años y, en particular, su relación con la expansión del mercado de alquiler informal ${ }^{6}$. En tercer lugar, se describe la estrategia metodológica utilizada para el desarrollo de la investigación que se centró en las villas 31 y 31 bis, 3 (Villa Fátima), 20, 21-24 y Rodrigo Bueno, localizadas en las comunas 1, 4 y 8 de la Ciudad de Buenos Aires. En cuarto lugar, y a partir de los datos obtenidos en el trabajo de campo, se caracteriza el perfil que asume la red de actores sociales que intervienen, tomando en cuenta a los inquilinos, oferentes de piezas en la villa y mediadores, a la vez que se describen las modalidades que adopta la práctica cotidiana del alquiler (arreglos económicos, precios del "contrato", percepciones sobre su situación habitacional). Por último, se interpreta el proceso desde el abordaje teórico de los conceptos de mercantilización/ des-mercantilización de bienes y servicios urbanos, recuperando algunas corrientes teóricas que reflexionan sobre la temática a escala regional.

\section{Ciudad neoliberal, ciudad mercantilizada. Ciudad para pocos}

Diversos autores de la sociología urbana (Herzer y Pírez, 1994; Rodríguez, 2005; Abramo, 2003) plantean que existen distintas lógicas de producción de servicios urbanos para acceder, habitar y

6 Vale aclarar que el mercado es uno solo (Portes, 1999). Aquí se toman las categorías analíticas "mercado formal" y "mercado informal" con el objetivo de dar cuenta de sus diversas dinámicas de funcionamiento. 
(re)producir la ciudad contemporánea latinoamericana: la lógica del mercado (orientada a la obtención de ganancia), la lógica del Estado (orientada por una racionalidad política o pública), y la lógica de la necesidad (orientada a la producción de un servicio urbano como bien de uso por fuera -0 parcialmente al menos- de las relaciones mercantiles). La apropiación del espacio urbano y de las externalidades que allí se concentran resulta de la interacción compleja y contradictoria de estas diferentes lógicas impulsadas por actores sociales con intereses contradictorios, de modo que las condiciones de apropiación y disfrute de la ciudad son social y políticamente producidas (Rodríguez et al., 2007; Clichevsky y Herzer, 1990).

Desde mediados de la década de 1970 las ciudades se convirtieron en lugares idóneos para el despliegue de transformaciones por las cuales pasaron a convertirse en objeto de negocio y especulación, en el marco de un extendido proceso de mercantilización de los bienes y servicios necesarios para la reproducción de vida. Varios autores -Amendola, (2000); Ascher, (2004); Castells, (2000); Harvey, (2004); Mongin, (2006); Sassen, (2002); Theodore, Peck y Brenner (2009)- definen a las ciudades como: ciudad posmoderna, global, informacional, neoliberal, pos-ciudad o pos-metrópolis, metápolis, exópolis, pos-urbana y sobre-moderna, marcando el pasaje de un tipo urbano industrial/ fordista hacia un modelo más complejo (el actual). La implantación del neoliberalismo dejó expuestas a las poblaciones de manera desigual a los efectos del desempleo, la degradación de los niveles de vida, la pérdida de recursos, así como de opciones y de calidades ambientales, al tiempo que "concentró la riqueza y el poder y más oportunidades políticas y económicas en unas cuantas localizaciones selectivas y dentro de unos cuantos estratos restringidos de población" (Harvey, 2003, p. 102). La nueva ciudad neoliberal no solo es escenario de reestructuración, sino que al mismo tiempo se convirtió en medio privilegiado de producción activa de desigualdad, en donde la producción social del hábitat, guiada por la lógica de la necesidad, se mantuvo como alternativa para los sectores populares $^{7}$. En una sociedad de mercado, las características de empleo e ingreso de los trabajadores juegan un papel preponderante en la definición de las posibilidades de consumo mercantilizado (Topalov, 1979) en el acceso a servicios urbanos.

El proceso de mercantilización supone el debilitamiento del derecho al acceso a bienes que requiere la población (Esping-Andersen, 1993). La reproducción de vida queda así supeditada a la capacidad

$7 \quad$ Entendemos por "sectores populares" a capas de población que viven de su capacidad de trabajo bajo arreglos crecientemente informales que se combinan, para la reproducción de sus vidas, con transferencias que reciben del aparato estatal. 
de pago, que a su vez depende básicamente de la inserción del trabajador en las relaciones salariales, principal fuente de recursos monetarios.

En mercados de trabajo, caracterizados por inserciones precarizadas y mal remuneradas, parte importante de la población se ve obligada a producir social y directamente su hábitat, orientados por la lógica de necesidad, desde procesos de consumo total o parcialmente desmercantilizados (Pírez, 2013). La toma de tierras y la consolidación de villas y asentamientos es un proceso social -no estatal- de producción de origen no mercantil de la provisión de bienes urbanos necesarios para la vida $^{8}$, que ha caracterizado históricamente el proceso de crecimiento y desarrollo de las ciudades latinoamericanas (Clichevsky, 1990). En el periodo más reciente, sobre esa lógica se sentaron las bases para la expansión de un mercado no solo de compra-venta, sino también de alquileres de inmuebles en las villas bajo prácticas y arreglos informales (Clichevsky 2000 y 2009). No son procesos mercantiles de producción urbana idénticos a los desplegados en el mercado formal, pero tampoco son actividades excluidas de la búsqueda de una ganancia. El inicial acceso no mercantil al suelo y/o a la vivienda puede incorporarse en el tiempo en proceso de mercantilización, como el que se despliega a lo largo de la última década, con el alquiler de piezas en las villas. Se consolidan así diferentes formas de re-mercantilización de procesos de producción que habían sido desmercantilizados, así como de mercantilización de bienes y procesos que estaban fuera de las relaciones mercantiles (Pírez, 2016).

Adicionalmente, este proceso conduce progresivamente a la privatización del suelo público y a su incorporación en la dinámica propiamente mercantil, situación que interpela la actuación del Estado y la definición de sus políticas en la temática.

\section{Villas en constante crecimiento. La informalidad}

Las villas en la Ciudad de Buenos Aires surgieron a partir de la década de 1930, a través de procesos des-mercantilizados de acceso a la vivienda, como una alternativa de ingreso a la ciudad y a las oportunidades asociadas a la localización de estas tipologías de hábitat (Kaztman, 1999).

8 Esto no quiere decir que procesos organizados por fuera de la lógica de ganancia no esté excluido de "interferencias" capitalistas, pues los habitantes de villas y asentamientos suelen adquirir materiales de construcción para sus viviendas e incluso acceso mediante compra de suelo a urbanizadores ilegales (sin documentación de propiedad o urbanización). 
Consideradas en un primer momento lugar "de paso" y "de emergencia" para sus residentes (Oszlak, 1991), a través de los años las villas se convirtieron en un lugar de permanencia, siendo para amplios sectores la única alternativa posible donde vivir en la ciudad (Rodríguez, 2015). El mayor pico poblacional se evidenció en el año 1976, con 213.823 habitantes, reduciéndose sustantivamente en los años siguientes con la implementación del plan de erradicación impulsado por la última dictadura militar (1976-1983), cuya población hacia 1980 mermó a solo 37.010 personas (Consejo Económico y Social de la CABA, 2013). A partir de los años ochenta, con la recuperación democrática, las villas de la ciudad volvieron a repoblarse de manera constante hasta la actualidad, generando cambios en su morfología y formas de acceso. A mediados de la década de 1990 comenzó un proceso de densificación en las villas tradicionales que, a causa del agotamiento de los predios vacantes en su expansión horizontal, impulsó un crecimiento en vertical acompañado de mecanismos mercantiles informales de compra-venta de viviendas y alquiler de piezas/ habitación, que se agudizaron durante la década siguiente (Cravino, 2006; Rodríguez, 2012).

Los datos actuales dan cuenta de esta tendencia. De acuerdo al censo 2010, la población en villas creció un 52.3\% (de 107.422 habitantes en 2001 a 163.587 en el año 2010), en su mayoría localizadas en la zona sur de la ciudad. La superficie total de la CABA hacia el año 2006 era de 20.300 hectáreas, de las cuales $1.46 \%$ del territorio está ocupado por villas (Cravino, Del Río y Duarte, 2008. p. 10). Mientras en la zona sur de la ciudad hay un 366\% más de población en villas y asentamientos que en la zona norte, hay también una superficie por metro cuadrado de $517 \%$ más en el norte que en sur 9 .

El proceso de expansión del mercado de alquiler en villas registra dos factores que presionaron estructuralmente (Bourdieu, 1997) a su surgimiento, consolidación y proliferación ${ }^{10}$, vinculados con las condiciones de vida de la población. Uno de ellos es el recrudecimiento, impulsado por una fuerte especulación inmobiliaria, de las

9 Interesa señalar que, con anterioridad al golpe militar de 1976 , este tipo de urbanización existía en barrios de la zona norte como Palermo y Colegiales, sin embargo, con la recuperación democrática (luego de la política dictatorial de erradicación llevada adelante) no volvieron a conformarse en esos lugares.

10 Es importante mencionar que también existe un significativo número de habitaciones/piezas en alquiler en hoteles pensión, inquilinatos y conventillos, pero, según los datos recolectados, no fue este sub-mercado el que mayor peso tuvo -en el último decenio - en el crecimiento de la tasa de inquilinos de la ciudad. 
condiciones de los contratos formales de locación ${ }^{11}$ y la evolución en alza de los valores de la vivienda en venta y en alquiler ${ }^{12}$. El otro factor es el deterioro progresivo de la capacidad adquisitiva de los ingresos de los trabajadores ${ }^{13}$ que, en promedio, destinan entre un tercio y el $50 \%$ del ingreso total familiar en alquiler ${ }^{14}$.

11 Esto equivale al costo de un mes de alquiler por adelantado más dos o tres de comisiones a inmobiliaria y gastos administrativos, más uno o dos de depósito, y garantía de propiedad de familiar directo en capital. Desde 2016, tras un fallo judicial, en concepto de comisiones y gasto administrativos no puede cobrarse más del $4.15 \%$ del total del valor del contrato.

12 Entre 2002 y 2014 el alza del precio del $\mathrm{m}^{2}$ para la venta representó un incremento promedio de $359.5 \%$. En el alquiler, en enero de 2014 el valor promedio de un departamento usado de tres ambientes fue de \$6.731. Al año anterior (enero 2013) la suba interanual representó el $35.1 \%$; y en relación al mismo periodo de 2009 el incremento representó el 63.9\% (Consejo Económico y Social de la Ciudad de Buenos Aires [CESBA], 2015). Adicionalmente se ofertaron distintas estrategias de acceso a la vivienda mediante la compra como créditos hipotecarios y garantías de bancarías para acceder al alquiler, pero todas fracasaron por las exigentes condiciones de ingreso a los programas (más información en CESBA, 2015).

13 Según la Encuesta Anual de Hogares 2012, el 6.2\% de los trabajadores era desocupado, mientras que el $8.5 \%$ era subocupado. Ahora bien, tampoco todos los trabajadores asalariados están registrados, pues el $26.7 \%$ de los trabajadores desempeña su actividad de manera informal (Rodríguez, 2013).

14 Sumado a la condición de precariedad relatada en la nota anterior, el Ingreso Total Familiar de un trabajador para el año 2012 fue de $\$ 8.289$ y en 2011 el $23.3 \%$ de los hogares tenía ingresos menores que los necesarios para acceder a la canasta total. Este escenario dificulta fuertemente la posibilidad de acceso a la vivienda formal (Rodríguez, 2013).
La informalidad remite fundamentalmente a una de las formas en las que se resuelve la relación capital/trabajo, proceso que a su vez provoca un cambio en la estructura socio-espacial y en la manera en que los sectores sociales resuelven su acceso al mercado de tierra y vivienda. La noción de informalidad desbordó las problemáticas asociadas con el mercado de trabajo y se hizo extensiva para caracterizar también la forma en que se resuelve la 
relación de sectores flexibilizados con el mercado de tierra y vivienda y con el sistema de propiedad (Herzer et al., 2007). La informalidad urbana se explica: i) por las condiciones macroeconómicas, como la falta de empleo, la baja salarial y el consecuente empobrecimiento de la población; y ii) por las políticas del Estado y el funcionamiento de los mercados de tierra urbana y vivienda (Clichersky, 2000 y 2009).

En este marco, Cravino define el mercado inmobiliario informal como

"transacciones inmobiliarias mercantilizadas (es decir monetizadas) que no están ajustadas a las normas legales y urbanas, y que no se convienen estrictamente a la lógica económica de la comercialización de inmuebles formal cuyos actores interactúan por fuera de las regulaciones económicas legales" (Cravino, 2006, p.40).

Siguiendo a la autora, en el marco legal las transacciones de compra-venta y alquiler constituyen una transferencia o arriendo del uso de hecho del inmueble, no ajustada al derecho o a las normas urbanas vigentes. Sin embargo, así se consolidan, por la vía de la costumbre, prácticas de apropiación del suelo público que se solapa con el reconocimiento y la legitimación de derechos de propiedad sobre las viviendas construidas sobre el mismo.

La definición de informal no supone adherir un dualismo sobre la existencia de un mercado formal versus otro informal. Por el contrario la informalidad es parte constituyente de la estructura productiva y territorial de la ciudad capitalista, que pone de manifiesto el carácter segmentado de un único mercado de trabajo y de tierra, que refleja la heterogeneidad constitutiva del sistema, y que acumula a partir del desarrollo geográfico desigual, inherente al despliegue de los mecanismos de mercado. Asimismo, existen acoplamientos y retroalimentaciones e interrelaciones entre el sector informal y el formal: por ejemplo, el sector formal provee capital e insumos al informal, mientras que los bienes y servicios producidos por este suelen ser consumidos por asalariados formales.

Ya sea que se trate del mercado de trabajo y/o del mercado inmobiliario, se hace referencia a agentes que no adhieren a las reglas institucionales establecidas, o bien, no entran bajo su protección (Herzer et al., 2007). Para los sectores de menores recursos, vivir en la capital -y en ciertas áreas con componentes de centralidad- se volvió un recurso más para la reproducción cotidiana de vida, y con ello, de acceso a estructuras de oportunidad (Kaztman, 1999) asociadas a la habitación (como el trabajo, la cultura, la salud, la educación, el esparcimiento, la cultura, etc.).

Estos tipos de mercados no están liderados por agentes intermediarios típicos (como inmobiliarias), sino que se trata de redes sociales en los barrios o, directamente, mediante la transacción "cara a cara" entre los habitantes de los mismos. Ahora bien, que 
no se ajusten a las normas estrictamente legales y urbanas no implica que no sigan lógicas capitalistas de funcionamiento. Además, en estos mercados, el Estado no establece regulación alguna ni ofrece herramientas de garantías hacia las partes. Incluso la intervención estatal con efecto mercantilizador puede promover relaciones informales de reproducción. Ejemplo de ello suelen ser los programas orientados a la emergencia mediante subsidios habitacionales, los cuales son utilizados por sus destinatarios para el pago de un alquiler informal de una pieza en una villa y/o un hotel.

\section{Abordaje metodológico: selección de casos y estrategias de recolección de datos}

La estrategia metodológica de esta investigación consistió en un abordaje combinado cuanti y cualitativo. Implicó la realización de un trabajo de campo en cinco villas de la Ciudad de Buenos Aires, llevado adelante entre los meses de julio y septiembre de 2015.

Se elaboró una encuesta de 120 preguntas (en su mayor parte cerradas), dirigidas exclusivamente a población inquilina en villas, con el fin de recabar información sobre las características físicas de las viviendas alquiladas, los arreglos económicos y los valores del alquiler, y una caracterización socio-económica del perfil de estos habitantes.

De este modo, se realizaron 304 encuestas distribuidas en cinco: las villas 31 y 31 bis (79 casos), Rodrigo Bueno (25 casos), 21-24 (100 casos), 20 (75 casos), y 3 ( 25 casos).

El criterio de selección de las villas respondió a su localización en las comunas 1, 4 y 8 , áreas caracterizadas por concentrar los mayores niveles de pobreza y criticidad habitacional, incluyendo varias de las más populosas y mejor localizadas en términos de accesibilidad urbana (Rodríguez, 2013). No se pretendió realizar un análisis en base a una muestra estadísticamente representativa, ya que se carecía de datos -oficiales y alternativos- y cartografía que permita delimitar el universo de la población inquilina en villas para poder establecer criterios de muestreo estadístico, a lo que se suman restricciones y temores que atraviesan a los inquilinos y dificultades de acceso de los investigadores a campo, en algunos casos. En cambio, se procedió a establecer un cuoteo para cada localización a partir de las orientaciones surgidas de las entrevistas con expertos y referentes de organizaciones sociales y comunitarias. Asimismo, se construyó el acceso a los inquilinos a través de una serie de dispositivos sociales y redes barriales (centros de salud, bachilleratos y comedores de variadas 


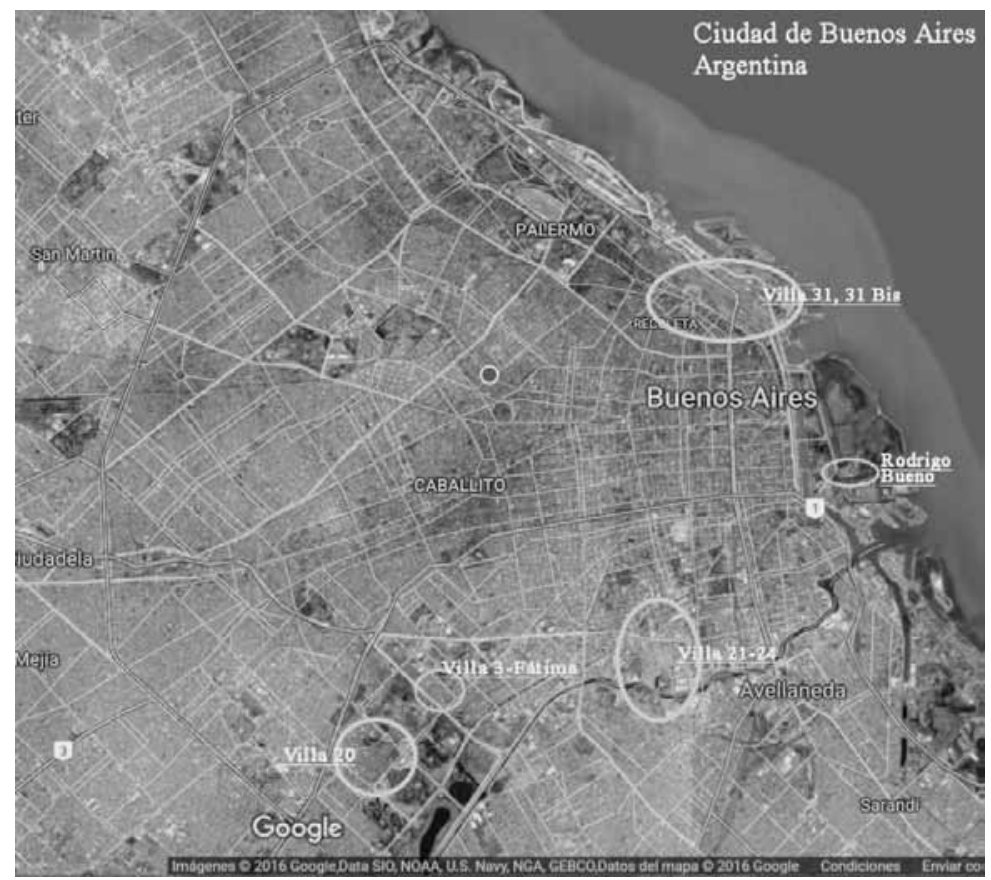

Mapa 1. Localización de casos de estudio. Villas 31 y 31 bis, 3 (Villa Fátima), 20, 21-24 y Rodrigo Bueno. CABA.

Fuente: Elaboración propia en base a Google Maps.

identidades y características socio-organizativas), configurando un marco de reserva, cuidado y anonimato y siguiendo el procedimiento "bola de nieve" entre los encuestados. Los encuestadores, configurando cinco equipos locales, fueron reclutados en el contexto de dicho entramado socio-organizativo y capacitados por el equipo de investigación, en talleres específicos.
Al intercambiar con ellos los objetivos de la investigación, también aportaron elementos de su propio conocimiento para lograr el acceso a una gama variada de inquilinos. Mediante esta estrategia, se logró generar un marco de confianza y seguridad para los encuestados inquilinos y, a la vez, un marco de viabilidad para la efectivización de la investigación. 
El trabajo de campo cuantitativo se complementó con una estrategia cualitativa, mediante la realización de 20 entrevistas semi-estructuradas a informantes clave (referentes barriales, integrantes de organizaciones sociales barriales, comedores, asociaciones gremiales sindicales, ONGs, funcionarios públicos locales y miembros de defensorías), que aportaron una contextualización de los ejes centrales de indagación de la encuesta. Los referentes barriales, quienes resultaron ser conocedores del funcionamiento del mercado de alquiler, efectuaron aportes significativos acerca de las características cualitativas de la oferta, que guiaron nuestra elaboración de una tipología de perfiles de locadores informales.

Estos insumos fueron acompañados por fuentes secundarias de información (informes técnicos, estudios producidos por universidades públicas y privadas), artículos periodísticos, así como información estadística de páginas oficiales del Estado -en sus distintas jurisdicciones-. Cabe señalar que las bases sistematizadas de estas fuentes, se apoyan en la línea de investigación longitudinal que el equipo desarrolla en la Universidad de Buenos Aires, referido en la nota 1.

\section{Los unos y los otros: una relación desigual}

En el mercado inmobiliario informal de las villas de la Ciudad de Buenos Aires, en primer lugar, intervienen dos actores sociales: el inquilino y el oferente de la vivienda.

En relación al perfil del inquilino en villa, uno de los entrevistados comentaba:

“... los que van alquilar son los que recién llegan o los de desglose familiar. Que también hay varios de desglose familiar: parejas que se constituyen y se van a vivir a alquilar y queda cerca de la familia, gente que se pelea con la familia y se va a vivir a alquilar ahí cerca, gente que vivía en zonas más periféricas y se viene a alquilar a la 31. Por ahí tiene la familia en el tercer cordón, tenés como de todo un poco. Pero de los que yo conozco alquilando tenés eso, tenés los hombres solos, pareja, pareja con hijo y madres solas, en general son madres con pibes" [Especialista en villas B. CABA, junio 2015].

En base a la encuesta realizada en las villas seleccionadas de la CABA, son fundamentalmente mujeres jefas de hogar las que se encuentran en esta situación de alquiler informal. De la población relevada, el $67.1 \%$ eran mujeres jefas de hogar, mientras que solo el $32.9 \%$ eran varones. 


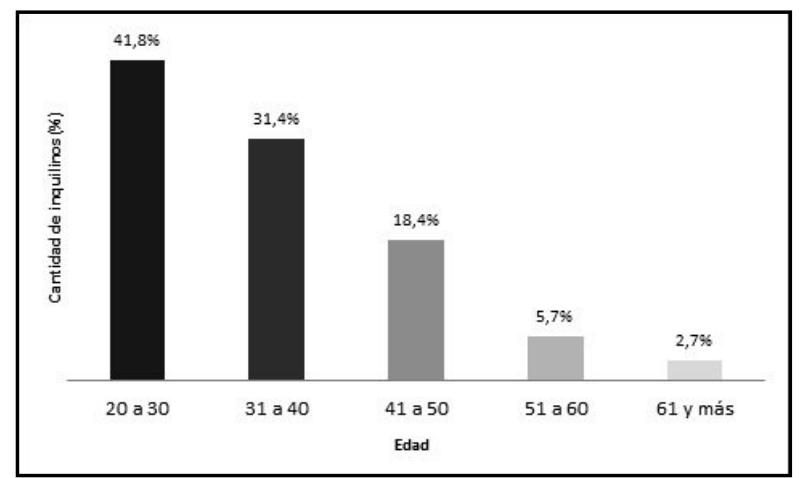

Gráfico 1. Inquilinos por edades. Total villas seleccionadas CABA. 2015

Fuente: Elaboración propia.

Las entrevistas detallaron que también son inquilinos las parejas jóvenes, que buscan su autonomización como desdoblamientos familiares (en los que priman las mujeres separadas/divorciadas con hijos menores a cargo) [Especialistas A y B, Referentes villas 3, 31 y 21-24. CABA. Junio-agosto 2015]. De las encuestas pudo relevarse que casi el $42 \%$ de los inquilinos poseen entre 20-30 años y el $31.4 \%$ entre $31-40$ años, mientras que un $26.8 \%$ representa una franja etaria de 41 años y más, lo que da cuenta de una población predominantemente joven, que inicia su trayectoria habitacional de manera autónoma en situación de alquiler informal.
Más de la mitad de la población relevada que alquila está casada o unida de hecho, representando un $54.6 \%$. El 38.8\% restante es soltera, mientras que el $6.6 \%$ se encuentra separada/divorciada $(4.6 \%)$ y viuda (2\%).

Con respecto a la nacionalidad, de acuerdo al censo 2010 la población de origen extranjero representa, para toda la ciudad, sólo el $13.2 \%$ de los habitantes, siendo las comunidades paraguaya, boliviana y peruana las que tienen mayor representación en un $21 \%, 20.1 \%$ y $15.8 \%$ respectivamente- con respecto al total de migrantes. Estas comunidades se localizan en mayor proporción en la comuna 1 (24.7\%), 8 (23.4\%) y 7 (18.6\%), que concentran las condiciones de mayor precariedad habitacional y existencia de villas y asentamientos en la urbe (Rodríguez, 2013).

Tal información se condice con los datos relevados en la encuesta realizada, pues el $67 \%$ de los inquilinos son migrantes, situación que demuestra cómo las villas se convierten en una estrategia central de acceso a la ciudad para quienes vienen de países cercanos. Ahora bien, desagregando este dato, al 33\% de la población inquilina de nacionalidad argentina, le siguen -en orden- los habitantes provenientes de Bolivia (29.4\%), Paraguay (22.4\%) y Perú (13.2\%). Una cantidad menor son de Uruguay, Chile y Colombia (lo que representa el $0.7 \%$ en cada caso). 
La preponderancia de argentinos en las villas da cuenta del cambio generacional que se percibe en los últimos años. Los migrantes extranjeros que se instalaron décadas anteriores en las villas de la ciudad tuvieron hijos argentinos; hoy muchos de ellos son los jóvenes que se encuentran en situación de imposibilidad de acceso a la vivienda y optan por el alquiler informal al momento de pensar en la independencia familiar.

Por su parte, la población inquilina de villas presenta los registros educativos más bajos: un alto porcentaje de la población que alquila no finalizó sus estudios secundarios, representando el 68.2\% del total (un total de 199 casos). No obstante, interesa señalar que un $4.5 \%$ de los inquilinos jóvenes cursa o cursó estudios universitarios ${ }^{15}$.

En relación a las características socio-económicas, el $77 \%$ de los inquilinos relevados respondió, al momento de la encuesta, haber trabajado al menos una hora la semana anterior. Del total de la población encuestada que trabaja, el 36\% son trabajadores especializados en algún oficio (orientados a la costura, actividades de servicios, seguridad y

15 Un estudio de la Universidad de Buenos Aires (UBA) en cuatro villas porteñas - 31 y 31 bis, $21-24,15,20$ - reveló que existen 500 jóvenes que estudian en la UBA o tienen intenciones de continuar estudios superiores. Las carreras más demandadas son enfermería, medicina, ingeniería y las referidas a las ciencias económicas y ciencias sociales (“De la villa", 2015). maestranza, entre otros); el 22.3\% son empleados domésticos; el 15\% son obreros calificados (de la industria textil, metalúrgica, de la construcción, de la confección y el calzado); y un 11.2\% empleados administrativos y vendedores (cajeros, trabajadores en comercio, administrativos).

En relación a sus salarios, del total de la población, el 43.8\% de los inquilinos manifestó tener un ingreso mensual promedio -en julio-agosto de 2015- del hogar de 3.601 a 7.200 pesos, mientras que el $41.8 \%$ se encontraban en una franja menor, de 1.301 a 3.600 pesos $^{16}$.

Un aspecto significativo de la población inquilina de villas es la informalidad que caracteriza a su condición de trabajadores signada por la precarización de la relación salarial y la ausencia de cobertura social. Si bien se observa cierto nivel de calificación en sus ocupaciones, los ingresos promedio del hogar son muy bajos y en condiciones de informalidad. El 69\% de los inquilinos manifestó no contar con descuentos jubilatorios, y casi un $70 \%$ no tenía cobertura de salud asignada por su empleador.

16 Estas cifras remiten a julio-agosto de 2015, periodo en el cual se realizó la encuesta en las villas de la ciudad, y dan cuenta de ingresos paupérrimos con relación al costo de vida porteño. En aquellos meses la canasta básica de alimentos por adulto equivalía a $\$ 1.153$ y de $\$ 3.563$ para una familia tipo de 2 adultos y 2 menores (Fundación de Investigaciones Económicas Latinoamericanas [FIEL], 2016). Un adulto, entonces, se gasta casi la mitad de sus ingresos solo en alimentos. 


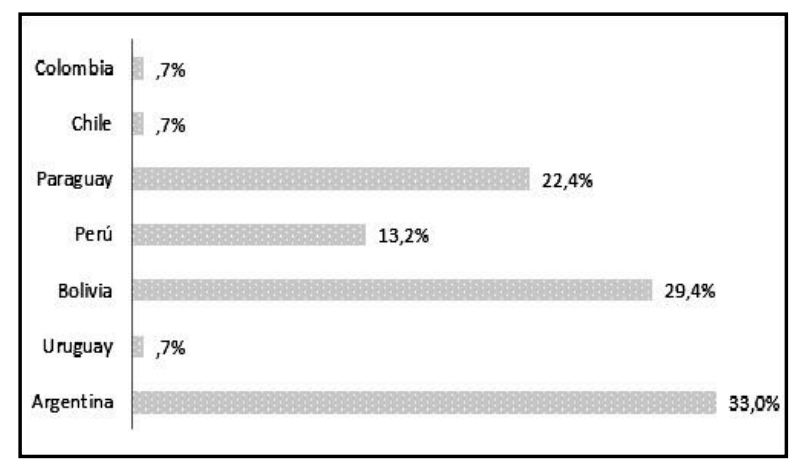

Gráfico 2. Nacionalidad de población inquilina. Total villas seleccionadas CABA 2015.

Fuente: Elaboración propia

En síntesis, los inquilinos en villas constituyen una población que acumula condiciones de vulnerabilidad, pues en su mayoría son mujeres jóvenes, jefas de hogar, migrantes, con bajo nivel educativo, y que se desempeñan como trabajadoras informales en el mercado laboral. También parejas jóvenes que buscan su independencia familiar y desgloses con símiles características. Esta acumulación de situaciones de precarización impacta en sus condiciones habitacionales y, evidentemente, restringe las posibilidades/alternativas de acceso a una vivienda digna.

Ahora bien, a partir de los resultados de la encuesta se pudo obtener que del total de la población encuestada el $81.3 \%$ reside en piezas, de los cuales un $47.7 \%$ alquila una pieza/habitación en casa de

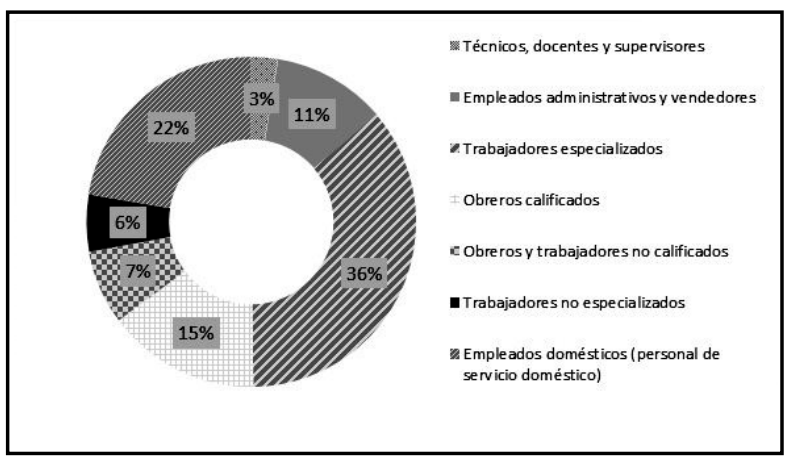

Gráfico 3: tipo de ocupación inquilinos. Total villas seleccionadas CABA 2015

Fuente: Elaboración propia.

familia, mientras que el 33.6\% declara residir en edificio construido para inquilinato.

Estas cuatro tipologías de hábitat ofrecidas en alquiler anuncian las características que asumen los perfiles de los oferentes de estos inmuebles, los cuales varían en función del capital invertido para el despliegue de esta práctica mercantil y las lógicas de producción que orientaron dicha inversión (desde lógicas estimuladoras de procesos estrictamente especulativos hasta lógicas vinculadas a una práctica de reproducción de la economía doméstica y las condiciones de subsistencia).

Uno de los especialistas entrevistado ensaya una interpretación sobre esta tipología de oferentes de vivienda en alquiler reconocida en la encuesta: 


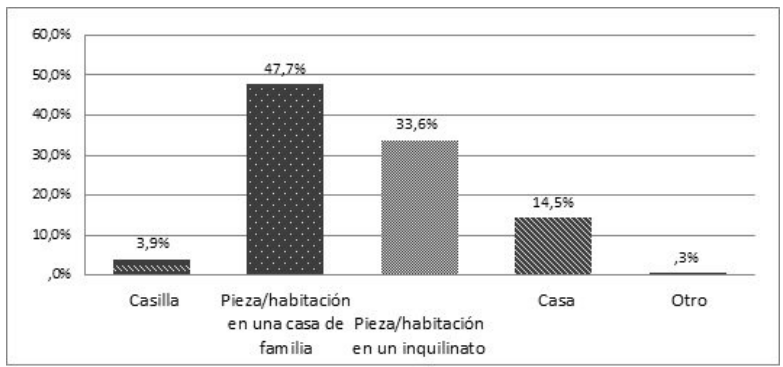

Gráfico 4. Tipo de vivienda que alquila. Total villas seleccionadas CABA. 2015

Fuente: Elaboración propia.

"... Y a medida que se acaba el suelo vacante [en la villa] se intensifica tanto el uso del suelo que existe, como la mercantilización del acceso a esa vivienda, y entonces va creciendo la modalidad de alquiler. Yo en la 31 no tengo una tipología muy determinada, pero me parece que puede pasar desde estas formas de alquiler de piezas...

Entrevistadora: ¿Estas vendrían a ser más estrategias familiares?...

Absolutamente, familiares, de supervivencia, pero muchas veces inclusive... Porque para mí hay dos, hay dos modalidades que son estrategias familiares de supervivencia. Una es que son -me da la sensación- casi de aprovechar una oportunidad que tengo una pieza vacía y aprovecho la oportunidad de alguien que me viene a preguntar y, bueno, alquilo. Y otro es que construye para arriba pensando en alquilar. Pero no construye un inquilinato... O sea, sabiendo que está construyendo para alquilar (...) incluso hay propietarios que no viven más en las villas o que dejan a alguien a cargo y ya tienen residencia afuera (...) Seguramente en inquilinato, que es la tercera modalidad, que ya son directamente emprendimientos inmobiliarios irregulares con fines de alquiler casi desligado de cualquier uso familiar, en algunos casos (por lo normal son los rumores de lo que dicen los vecinos) pero el edificio se enteró que están destinados exclusivamente al alquiler que ya es otra cosa..." [Especialista en villas B. CABA, junio 2015].

"...el crecimiento en los barrios (...) viene acompañado de la inversión de los que tienen capacidad de invertir, que son grupos organizados en los barrios para generar esas habitaciones. Y eso para mí se enmarca, te diría yo... yo lo identifique más, más tardío... De 2008 en adelante... pero también se explica porque hay una lógica... la gente entra en la misma cuando sus hijos crecen, no hay solución habitacional, entonces, ¿qué hago? Le construyo una pieza arriba. Para él y su familia. Y después tengo mis nietos y mis nietos crecen... la misma lógica del crecimiento del conurbano... Hay como una lógica de ampliar la casa para la descendencia, pero eso también hace previsible o hace más palpable la lógica de poder ampliar la casa para alquilar" [Especialista en villa A. CABA, julio 2015].

En este sentido, se pudo detectar la existencia de al menos tres perfiles de oferentes de vivienda en alquiler informal:

1.Un primer perfil caracterizado por familias que viven tradicionalmente en la villa y que, como resultado de la recuperación económica que vivió la 
Argentina en los últimos años (2003-2007), lograron a través de sus ahorros construir habitaciones/ piezas como extensión de sus propias viviendas para ofrecerlas en alquiler garantizándose así algún tipo de ingreso fijo. Incluso en el trabajo de campo realizado se hizo mención a la necesidad de ir generando algún tipo de "fondo familiar que funcione como jubilación cuando ya no se pueda trabajar más" [Referente Villa 3-CABA, agosto 2015]. Si bien este tipo de oferentes de inmuebles en alquiler está motorizado desde una lógica de obtención de ingresos a partir de una renta, dicha práctica está arraigada en una estrategia doméstica de subsistencia en un contexto de precarización y vulnerabilidad.

2.Un segundo perfil vinculado a agentes "cuasi" inmobiliarios que construyen y alquilan a mayor escala en las villas, como modalidad de inversión y obtención de una ganancia especulativa. Esta tipología remite a grandes inquilinatos con oferta de hasta 30/50 habitaciones en alquiler, con baño y cocina compartida (y casillas en ciertas localizaciones). Se trata más bien de unidades funcionales destinadas al mercado de alquiler informal. Aquí se está frente a un perfil de oferentes orientados por una lógica de obtención de renta a partir de un proceso de especulación inmobiliaria, donde hay una máxima asimetría en la relación "inquilino-propietario". Un entrevistado de la Villa 31 manifestó que son estos oferentes - que no viven en la villa pero realizan sus negocios inmobiliarios en ella- los que rechazan e imposibilitan cualquier tipo de intervención estatal de cara a un proceso de urbanización [Referente Villa 31-CABA, julio de 2015]. Un tipo de intervención -local o estatal- de estas características pone en riesgo la renta extraordinaria que obtienen con su negocio inmobiliario informal ${ }^{17}$.

3.El tercer perfil identificado remite a familias que con la recuperación económica del país lograron irse del lugar en busca de una mejor calidad de vida, pero mantienen en "propiedad"18 sus casas dentro de la villa para alquilarlas. La mayoría de las veces, estos oferentes dejan a un encargado en

17 En las villas más pequeñas este tipo de oferentes de inmuebles no es una práctica extendida. Son fácilmente localizables en villas más grandes. Los vecinos de la villa 31 , e incluso algunos de los especialistas consultados, advierten que el nuevo barrio San Martín -producto de la última toma de tierra vacante de 2010 es un barrio exclusivamente conformado por inquilinatos.

18 El encomillado remite a que, si bien en los pasillos de la villa se diferencian los distintos grupos sociales como propietarios e inquilinos, solo poseen lo construido sobre el suelo de propiedad pública o privada. 
su antigua vivienda para su administración. Aunque este tipo de oferente también está orientado por una lógica de obtención de renta, a partir de un proceso de especulación inmobiliaria, se considera importante reconocer la diferencia de escala con relación al caso anterior.

En suma, si bien estos tres perfiles de oferentes de vivienda en alquiler conviven en las villas de la ciudad, tienen diferencias sustantivas en término de capitales de inversión, lógicas de producción que las engendraron y formas en que operan en el territorio. Diferenciar estas lógicas aporta a la peculiaridad que asume este mercado inmobiliario informal que introduce una mayor heterogeneidad en los actores del entramado villero que se traduce en la profundización de desigualdades sociales y territoriales dentro de las villas. En este sentido, planteamos que las relaciones de reciprocidad identificadas y caracterizadas por Abramo (2009) y Cravino (2006), que se corresponden con procesos de subjetivación de los mercados informales (Dienger, 2016), mediados por lazos de parentesco, reciprocidad, cooperación, etc. comienzan a convivir con la lógica del negocio de edificios construidos para uso exclusivo de inquilinato, donde las fronteras entre la ilegalidad y la informalidad se opacan, favoreciendo oportunidades de ganancias expoliativas que, a la vez, precarizan y deterioran la sociabilidad.

Como intermediarios de las relaciones mercantiles informales presentes en todos los tipos -y no refrendadas en ningún papel que acredite cierta legalidad-aparece mencionado recurrentemente en las encuestas otro actor presente en el territorio: el delegado por manzana, que actúa como mediador o testigo del acuerdo entre las partes, y es quien oficiará de intermediario ante cualquier inconveniente durante el alquiler. Las características y funciones que asume este tercer actor aún son objeto de profundización por nuestras investigaciones, pero a priori, los delegados, electos por los propios vecinos, constituyen su representación social y territorial (en muchos casos, amparados por marcos legales que reconocen la organización de la población villera). Sin embargo, el ejercicio de este rol en contextos de alta fragmentación, puede conducir a prácticas de punterismo o tender a asimilarse con el de personal estatal descentralizado. 


\section{Productos ofrecidos, arreglos económicos y percepciones en torno al mercado de alquileres en villas}

Como ya señalamos, la práctica del alquiler informal no implica un arriendo con un título de propiedad que sirve de respaldo legal de la transacción realizada, sino que trata de una transferencia de hecho del uso del inmueble. La legitimidad de la transacción no descansa en un contrato ajustado al marco legal vigente, sino en la ocupación de hecho del inmueble por parte del inquilino mediante un acuerdo de palabra, o donde auspicia de testigo el delegado de manzana (muy referido en las encuestas y entrevistas realizadas), o incluso bajo algún tipo de "documento" escrito entre las partes. Del relevamiento realizado, se registró que el 93.8\% de los inquilinos se encontraba en esta situación. Solo el 5.3\% de los encuestados reveló contar con algún tipo de "contrato" que respalde la transacción, pero las características de estos tipos de documentos son un aspecto a indagar y profundizar en futuros trabajos.

En este tipo de transacciones no intervienen agentes intermediarios típicos como inmobiliarias (que capturan parte del monto de la transacción o publican sus avisos de alquiler en periódicos de tirada masiva), sino que operan -como modalidad de acceso al alquiler- las redes sociales ancladas en el territorio de los barrios o directamente los contactos cara a cara entre los habitantes. De los encuestados, casi el 90.5\% se enteró de la vivienda que alquila por un amigo, conocido o familiar mientras que los restantes accedieron mediante algún cartelito pegado en la iglesia, comercio o pasillos del barrio. Esta particularidad, posibilita cierta flexibilidad en términos de la modalidad de pago y a repactarse las condiciones del contrato sucesivas veces a medida o necesidad de algunas de las partes.

Estas transacciones se caracterizan también por un alto grado de inmediatez en su acceso, pues no requiere el pago de una reserva ni de averiguación de antecedentes ni presentación de una garantía, aunque en algunos casos se exige un depósito por roturas del inmueble (más aún si se ingresa con niños).

Ahora bien, la ilegalidad que atraviesa esta relación se encuentra en estrecha vinculación con los orígenes des-mercantilizados de las villas, surgidas y consolidadas por fuera de cualquier tipo de regulación estatal, y por ende de las normas de uso del suelo urbano. Las condiciones de habitabilidad en las villas y asentamientos de la ciudad de Buenos Aires de por sí vulneran, precarizan y complejizan la capacidad de reproducción de vida de las familias que allí se asientan. Esta situación se agrava para los inquilinos, pues la construcción 
de las viviendas a las que acceden están mediatizadas por una lógica especulativa de obtención de ganancia por sobre la prestación de calidad habitacional, y por ende, de vida. Los inmuebles ofrecidos, en gran parte, tratan de habitaciones de dimensiones pequeñas $(2 \times 4 \mathrm{~m}$ promedio una habitación chica, o $3 \times 6 \mathrm{~m}$ promedio una habitación grande), con baño y cocina compartidos.

La mayoría de las familias cuentan con un aparato de cocina en sus habitaciones, pues el 93.4\% utiliza gas en garrafa para cocinar. Con respecto a los sanitarios, solo un 58\% accede a un baño exclusivo para su hogar, aunque al indagar las características del mismo, solo remite a un inodoro y lavatorio (la ducha es compartida). No cuentan con limpieza de los espacios comunes en los gastos del alquiler y solo la mitad de los encuestados dijo contar con recolección de basura. Entre los materiales de construcción que predominan en paredes, pisos y techos son el cemento y ladrillo revestido, incluso solo la mitad de los inquilinos encuestados poseen techo con revestimiento interior. En general la ventilación de las habitaciones fue evaluada como de regular a mala por los encuestados. La villa 31 pareciera ofrecer mejores condiciones constructivas (además de una excelente localización), mientras que las villas relevadas de comuna 8, las peores.
Los inquilinos poseen altos niveles de cohabitación. Las villas 20, 21-24 y Rodrigo Bueno son las que presentan la mayor cantidad de inquilinos cohabitando, es decir, con más de una familia como hogar $(24.3 \%, 24 \%$ y $20.8 \%$ respectivamente), en contraposición a las villas 31 y 3 (7.5\% y $3.8 \%)$. El 75.3\% de los habitantes encuestados manifestaron que su hogar está conformado entre uno y cuatro integrantes compartiendo habitación, mientras que el $24.8 \%$ restante cuentan con más de cinco personas en su hogar. La comuna 8 evidencia el mayor porcentaje de inquilinos con hogares de más de cinco integrantes (35.4\%).

Ahora bien, por el contrario de lo que indica el sentido común, la mala calidad de habitabilidad que reproduce la villa no impacta en bajos costos de vida para los inquilinos. Esto se refleja en los valores de locación, los cuales -a pesar de su informalidad- no logran escapar a la lógica especulativa del mercado.

La encuesta evidencia que, hacia mitad del año 2015, el 73.3\% de la población inquilina pagaba entre 500 (USD 52) y 1.500 (USD 156) pesos por su pieza/habitación y el $26.8 \%$ entre 1.501 (USD 156.3) y más ${ }^{19}$. El alquiler promedio por pieza es de 1.400 pesos (USD 146), lo que representa el 25\% del salario mínimo vital y móvil \$5588 (USD

19 La conversión pesos argentinos-dólar oficial es de 9.60 pesos ARG = 1 USD, a noviembre de 2015. 


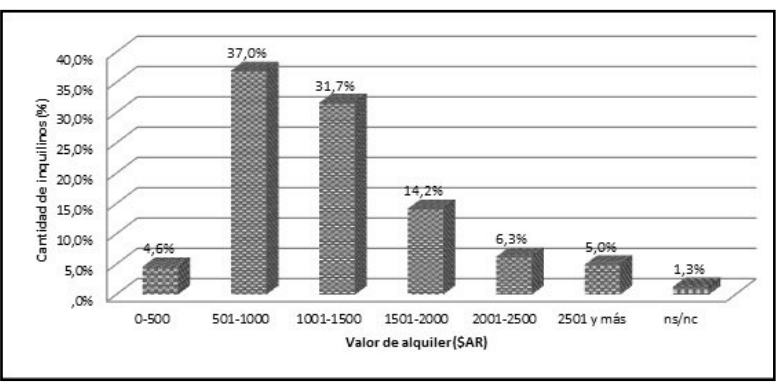

Gráfico 5. Valores de alquiler en villas (pesos argentinos). Total villas seleccionadas CABA. 2015.

Fuente: Elaboración propia

582) ("Resolución 4", 2015). La variación de los precios está determinada, fundamentalmente, por la localización de las habitaciones (los inmuebles más cercanos al ingreso/salida de la villa o de los corredores centrales presentan los valores más altos en detrimento de las habitaciones "del fondo)"; la tenencia de ambientes -baño y cocina- exclusivos y otras comodidades (recolección de residuos, calefacción, acceso a terraza, internet, entre otros).

A su vez, el $47.7 \%$ de la población se ve afectada por reactualizaciones anuales en el monto del alquiler. A un $24.9 \%$ le aumentan más de una vez al año, mientras que el $16.9 \%$ aún no ha tenido aumento por haberse instalado en el lugar recientemente, pues los inquilinos están expuestos a residir de manera intermitente en sus viviendas, trasladándose de una vivienda a otra, ante la falta de protección y resguardo legal de las arbitrariedades de los oferentes. Más de la mitad de los inquilinos (51.9\%) aduce que los aumentos son definidos de manera unilateral.

Los altos niveles de arbitrariedad que posee el oferente de las viviendas, ante la falta de algún contrato legal que garantice los derechos de los inquilinos, repercute en que el $26.4 \%$ de los inquilinos encuestados expresa un alto riesgo a ser desalojado. Al indagar los motivos que originan estos posibles desalojos, se relevó: incumplimiento de las condiciones acordadas de alquiler (31.3\%), recibir asiduamente visitas (12.5\%), deterioro de las condiciones habitacionales (12.5\%), contar en el núcleo familiar con niños que pueden incomodar a los vecinos (12.5\%), entre otros. Entre los que argumentaron que no siente riesgo a ser desalojos, predominó el "cumplir con las condiciones exigidas de pago" (35.1\%) y "el propietario es un conocido/un familiar" (17.9\%) -resaltando la dinámica de redes que existe para el acceso-. Estos datos asumen importancia si se tiene en cuenta que para el $86 \%$ de los inquilinos la vivienda que alquila es su principal residencia.

Por último, entre los principales motivos de residencia en las viviendas en alquiler, la mayoría de los inquilinos argumentaron: "no tener garantía para un alquiler formal" (28.3\%); "por trabajo" (24.3\%); "por familia" (21.7\%), "por no trabajar en blanco para un alquiler formal" (9.2\%). Un $37.5 \%$ de los encuestados que alquilan en la villa, 
declaraban que quisieran hacerlo en la ciudad formal, pero, como se vio anteriormente, las condiciones de acceso al mismo son las que constriñen a la expansión de la informalidad.

\section{Conclusiones: alquileres informales y desafíos para las políticas de urbanización e integración en villas}

La dinámica urbana de los países latinoamericanos no solo se ha centrado en la particularidad de expandir sus espacios urbanos vía procesos formales de urbanización sino también a través de dinámicas ligadas a la producción social del hábitat, de parte de los sectores populares, bajo la lógica de la necesidad de reproducción de la vida.

Ahora bien, como se desarrolló a lo largo del trabajo, las estrategias de producción de ciudad que en sus orígenes dieron cuenta de procesos des-mercantilizados de bienes y servicios urbanos, con el tiempo fueron desplegando en su interior dinámicas estrictamente mercantilizadoras de acceso a la vivienda, que en muchos de los casos incluso fueron estimuladas indirectamente por la intervención estatal (Pírez, 2016). En un contexto de "consumo mercantilizado", la dinámica de valorización del suelo y el recrudecimiento de las condiciones de acceso, el aumento de los alquileres formales y la falta de políticas públicas orientadas al acceso a una vivienda digna, impulsaron a las familias trabajadoras precarizadas con bajos ingresos a acudir a las villas bajo modalidad de alquiler informal.

Este artículo pudo dar cuenta que la inquilinización en las villas es parte constituyente de un proceso mercantil de producción urbana en el que existen distintos perfiles de actores $s$ orientados a la búsqueda de rentas. El modo en el que las transacciones se despliegan en el territorio marca disparidades, a través de un conjunto de circuitos, condiciones y arreglos económicos que se basan en la naturalización de prácticas expoliativas sobre los grupos más vulnerables.

La ausencia de un marco legal y urbano sumada las barreras de ingreso al mercado formal de venta y alquiler fueron consolidando en las villas, distintos tipo de oferentes de inmuebles que estuvieron estimulados a participar en este mercado. Si bien algunas familias participan desde una lógica de subsistencia, otros se articulan plenamente sobre la obtención especulativa de rentas explotando las vulnerabilidades de los inquilinos. Asimismo se pudo verificar que los inquilinos son los más vulnerados de la población villera, ya que remite a un grupo social en el que son mayoría mujeres, 
jóvenes, migrantes, jefas de hogar (pero también parejas jóvenes que se independizan o familias que se desdoblan), y trabajadores informales, con bajo nivel educativo.

Se resalta la existencia de un submercado de propiedades construidas para alquiler, de carácter especulativo y capital de origen incierto, empezando por el tráfico de drogas, donde la ilegalidad se invisibiliza, confunde y prospera bajo el manto de la informalidad y la pobreza. Como señala Clichevsky (2000) en su estudio comparativo en ciudades latinoamericanas, la posibilidad de existencia de mercados ilegales está directamente vinculada con acciones del hacer y no hacer estatal, como el clientelismo, al punterismo político y los réditos -traducidos en votos que se puedan conseguir-o asociaciones de negocios. La escasa transparencia del mercado de tierras en su totalidad, se exacerba en este mercado particular.

Adicionalmente, esta mirada de prácticas mercantiles consolida el proceso de apropiación privatizadora del suelo público, ya que las prácticas y percepciones no desglosan el suelo de las viviendas construidas, como lo hacemos los investigadores en las categorías censales. La venta de superficies construibles en altura, práctica mencionada por nuestros entrevistados, da una idea clara de cuán internalizada se encuentra la lógica de valorización del suelo, extensiva al suelo "creado" sobre superficies construidas. Aquí no hay ingenuidades, hay mercado.

Este conjunto de prácticas y arreglos institucionales informales interpelan directamente a la dinámica de funcionamiento del mercado inmobiliario formal (tanto en sus aspectos económicos como legales) y en particular a la lógica inmobiliaria de valorización del suelo.

Es probado en América Latina que la regularización dominial no altera las condiciones perversas en que se produce la ciudad; no elimina las prácticas ilegales $y$, si no es acompañada de propuestas integrales de intervención, las recrea y retroalimenta (Clichevsky, 2000). Si las políticas públicas de integración urbana que se proponen la "regularización dominial" y la "integración urbana", reconocen y legitiman sin mediaciones este conjunto de arreglos mercantiles informales, tenderán a incorporarlos al mercado formal, legitimando el proceso de privatización que reafirma la lógica de segregación del mercado inmobiliario y que sostienen su dinamización y la reproducción de desigualdades socioeconómicas constituidas a partir de la apropiación y sobre la base de activos del patrimonio público que son un bien común de nuestra sociedad. 


\section{Referencias bibliográficas}

Abramo, P. (2003). A cidade da informalidade. O desafio das cidades latinomericanas. Río de Janeiro: Lincoln Institute, Sette Letras, Faperj.

(2009). Mercado e favela: a nova porta de entrada dos pobres nas cidades brasileiras. Porto Alegre: Habitare, Finep, Antac.

Amín, S. (2003). Más allá del capitalismo senil. Por un siglo XXI no norteamericano. Buenos Aires: Paidos.

Amendola, G. (2000). La ciudad posmoderna. Madrid: Celeste.

Ascher, F. (2004). Los nuevos principios del urbanismo. Madrid: Alianza.

Bourdieu, P. (1997). Razones prácticas. sobre la teoría de la acción. Barcelona: Anagrama.

Castell, M. (2000). Globalización, sociedad y política en la era de la información. Bitácora Urbano Territorial, 1(4), 42-53.

Clichevsky, N. (2000). Informalidad y segregación urbana en América Latina. Una aproximación. Santiago de Chile: CEPAL.

(2008). Acceso a la tierra urbana y políticas de suelo en el Buenos Aires metropolitano. Apuntes para la reflexión. riURB Revista Iberoamericana de Urbanismo, (8), 59-72. Recuperado de http://hdl. handle.net/2099/13034.

(2009). Algunas reflexiones sobre informalidad y regularización del suelo urbano. Bitacora
Urbano Territorial, 1(14), 63-88. Recuperado de https://revistas.unal.edu.co/index.php/bitacora/ article/view/18508.

Clichevsky, N. y Herzer, H. (1990). Construcción y administración de la ciudad latinoamericana. Buenos Aires: IIED-AL.

Consejo Económico y Social de la Ciudad de Buenos Aires. (2015). La ciudad de Buenos Aires inquilinizada. Un análisis del mercado inmobiliario en la última década y del alquiler como estrategia de acceso a la vivienda en la CABA. Buenos Aires: Autor. Recuperado de http://www.bdigital.cesba.gob.ar/ handle/123456789/90

Cravino, C. (2006). Las villas de la ciudad. Mercado e informalidad urbana. Los Polvorines: UNGS.

Cravino, C., Del Río, J.P., y Duarte, J. (2008). Magnitud y crecimiento de las villas y asentamientos en el Área Metropolitana de Buenos Aires en los últimos 25 años. En Encuentro de la Red Universitaria Latinoamericana de Cátedras de Vivienda. Buenos Aires: Universidad de Buenos Aires, Facultad de Arquitectura, Urbanismo y Diseño.

De la villa a estudiar una carrera (2015, 5 de marzo). Página 12. Recuperado de https://www.paginal2. com.ar/diario/sociedad/3-267403-2015-03-05. html.

Dienger, M. (2016). Dinámica en el mercado inmobiliario informal. Análisis sobre la villa 31. (Tesis de licenciatura, Universidad de San Andres, Colombia).

Esping-Andersen, G. 1993. Los tres mundos del estado del bienestar. Valencia: Edicions Alfons el Magnánim. 
Fundación de Investigaciones Económicas Latinoamericanas. (2016). Canasta Básica Alimentaria (CBA) y Canasta Básica Total (CBT) para la ciudad autónoma de Buenos Aires (CABA) Mayo 2016. Buenos Aires: Autor. Recuperado de http://www.fiel.org/publicaciones/canasta/CAN_BAS_1464984580715. pdf.

Harvey, D. (2003). Espacios de esperanza. Madrid: Akal.

(2004). El «nuevo» imperialismo: acumulación por desposesión. Socialist Register, 40, 63-89. Recuperado de https://socialistregister.com/index. php/srv/article/view/5811.

Herzer, H., Di Virgilio, M., Lanzetta, M., Martín, L., Redondo, A., Rodríguez, C., e Imori, M. (2007). El proceso de renovación urbana en La Boca: organizaciones barriales entre nuevos usos y viejos lugares. Memoria y Sociedad, 11(22), pp. 1936. ISSN electrónico 2248-6992. ISSN impreso 0122-5197.

Herzer, H. y Pírez, P. (1994). Gestión urbana en ciudades de tamaño medio de América Latina. Nairobi: Hábitat-ONU.

Kaztman, R. (1999). Activos y estructuras de oportunidad. Estudio sobre las raices de la vulnerabilidad social en Uruguay. Montevideo: CEPAL-PNUD.

Mongin, 0. (2006). La condición urbana. La ciudad a la hora de la mundialización. Buenos Aires: Paidós.

Oszlak, 0. (1991). Merecer la ciudad. Los pobres y el derecho al espacio urbano. Buenos Aires: Hvumanitas-Cedes.
Pírez, P. (2013). Servicios urbanos en América Latina: la urbanización popular. En 20 años de pensar y repensar la sociología. Nuevos desafíos académicos, científicos y politicos para el siglo XXI. Buenos Aires: Universidad de Buenos Aires.

(2016). Las heterogéneas formas de producción y consumo de la urbanización latinoamericana. Quid16, (6), 131-167.

Portes, A. (1999). La economía informal y sus paradojas. En J. Carpio, E. Klein, e I. Novacovsky (Comps.) Informalidad y exclusión social. Argentina: Fondo de Cultura Económica y Secretaría de Desarrollo Social de la Nación.

Pradilla Cobos, E. (2010). Teorías y políticas urbanas iLibre mercado mundial, o construcción regional. Revista Brasileira de Estudos Urbanos e Regionais, 12(2), 9-21. http://dx.doi. org/10.22296/2317-1529.2010v12n2p9.

Resolución 4, el Consejo Nacional del Empleo actualiza el Salario Mínimo, Vital y Móvil para todos los trabajadores. Boletín Oficial, Argentina, 24 de Julio de 2015. Recuperado de http://www.saij.gob.ar/consejo-nacional-empleo-actualiza-salario-minimo-vital-movil-para-todos-trabajadores-consejo-nacional-empleo-actualiza-salario-minimo-vital-movil-para-todos-trabajadores-nv12114-2015-07-21/123456789Oabc-411-21ti-lpssedadevon

Rodríguez, F. (2012). Entre la omisión y la expulsión. Un análisis sobre las modalidades de intervención estatal en los Nuevos Asentamientos Urbanos (NAU). En H. Herzer, Barrios al sur. Renovación y 
pobreza en la Ciudad de Buenos Aires (pp. 73-94). Buenos Aires: Café de las Ciudades.

(2015). El papel de la localización en las disputas por el espacio urbano: accionar estatal y prácticas organizativas en villas tipificadas «como no regularizables» de la ciudad de Buenos Aires, 2001-2015. (Tesis de doctorado, sin publicar). Universidad de Buenos Aires, Buenos Aires.

Rodríguez, M.C. (2005). Como en la estrategia del caracol... Ocupaciones de edificios y politicas locales de hábitat en la ciudad de Buenos Aires. Buenos Aires: El cielo por asalto.

(Coord.) (2013). Diagnóstico socio-habitacional de la ciudad de Buenos Aires. Buenos Aires: CESBA. Recuperado de http://bdigital.cesba.gob.ar/ handle/123456789/71

Rodríguez, M.C., Di Virgilio, M.M., Procupez, V., Vio, M., Ostuni, F., Mendoza, M., y Morales, B. (2007). Politicas del hábitat, desigualdad y segregación socioespacial en el Área Metropolitana de Buenos Aires. Buenos Aires: Universidad de Buenos Aires, Facultad de Ciencias Sociales, Instituto de Investigaciones Gino Germani.

Sassen, S. (2002). Locating cities on global circuits. Environment \& Urbanization, 14(1), 13-30. https:// doi.org/10.1177\%2F095624780201400102.

Theodore, N, Peck, J. y Brenner, N. (2009). Urbanismo neoliberal: la ciudad y el imperio de los mercados. Temas Sociales, (66), 1-12.

Topalov, C. (1979). La urbanización capitalista. Algunos elementos para su análisis. México: Edicol. 